\title{
Молекулярные и клеточные механизмы воспаления при подагре
}

\author{
Малышев И.Ю., ${ }^{1,2}$ Пихлак А.Э. ${ }^{1}$, Буданова О.П. ${ }^{2}$
}

\author{
'Федеральное государственное бюджетное образовательное учреждение высшего образования \\ «Московский государственный медико-стоматологический университет имени А.И.Евдокимова» \\ Министерства здравоохранения Российской Федерации. \\ 127473, Москва, ул. Делегатская, д. 20, стр. 1 \\ ${ }^{2}$ Федеральное государственное бюджетное научное учреждение \\ «Научно-исследовательский институт общей патологии и патофизиологии». \\ 125315, Москва, ул. Балтийская, д. 8
}

В обзоре проанализированы механизмы подагрического воспаления и разрешения острого воспаления при подагре, и то, как их понимание способствует созданию новых технологий лечения подагры. $B$ первой части обзора анализируется кристалл-индуцированное воспаление при подагре, которое связано с активацией инфламмасомы NLRP3 в макрофагах, состоящее из двух этапов: 1) синтез компонентов инфламмасомы; и 2) сборка инфламмасомы. Проанализированы сигналы, активирующие синтез компонентов инфламмасомы, которые генерируются при взаимодействии кристаллов урата мононатрия с макрофагами. Описаны этапы инициации воспаления при пода-

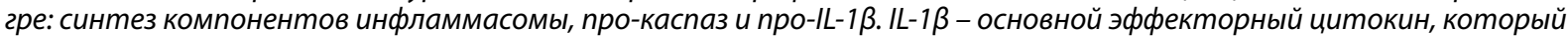
запускает не только воспалительный ответ, но и вызывает вазодилатачию сосудов, привлечение нейтрофилов к месту отложения кристаллов и еще больщее усиление острого воспалительного эпизода через TLR-зависимую активачию NF-кB (фактор транскрипчии).

Рассматривается роль растворимой мочевой кислоты в активачии инфламмасомы NLRP3. Подчёркнуто, что в разрешении острого воспаления при подагре основную роль играют те же клетки, что и в развитии классической воспалительной реакции: макрофаги и нейтрофилы. В обзоре рассмотрены сигнальные пути, которые переключают воспалительный ответ на разрешение и завершение воспаления: АМРК- (АМР-активируемая киназа) зависимый путь; антивоспалительные цитокины TGF $\beta 1$, IL-10 и IL-1Ra; белок аннексин A1 (AnxA1) и а1-антитрипсин (AAT). Onuсаны способы терапевтического блокирования воспаления при подагре с помощью ингибиторов инфламмасомы и ингибиторов IL-1 $\beta$. Изучение механизмов подагрического воспаления и его разрешения привело к идее о разработке методов репрограммирования иммунных клеток и адаптивной иммунотерапии подагры, методов, которые при других заболеваниях, таких как рак, уже показали выдающиеся возможности лечения больных.

Ключевые слова: подагра; инфламмасома; нейтрофилы; макрофаги; кристаллы мочевой кислоты; IL-1 $\beta$.

Для цитирования: Малышев И.Ю., Пихлак А.Э., Буданова О.П. Молекулярные и клеточные механизмы воспаления при подагре. Патогенез. 2019; 17(4): 4-13

DOI: $10.25557 / 2310-0435.2019 .04 .4-13$

Для корреспонденции: Малышев ИгорьЮрьевич, e-mail: iymalyshev1@gmail.com

Финансирование: Написание обзора поддержано Российским фондом фундаментальных исследований (РФФИ) по результатам конкурсного отбора научных проектов в качестве победителя конкурса ЯМИФ_т - Конкурс проектов 2018 г. фундаментальных научных исследований, проводимый совместно РФФИ и Японским фондом медицинских исследований, Договор № 18-515-57003\18 от 24.05.2018

Конфликт интересов. Авторы заявляют об отсутствии конфликта интересов

Поступила: 11.04 .2019

\section{Molecular and cell mechanisms of inflammation in gout}

\author{
Malyshev I.Yu. ${ }^{1,2}$, Pihlak A.E. ${ }^{1}$, Budanova O.P. ${ }^{2}$
}

\begin{abstract}
${ }^{1}$ A.I. Evdokimov Moscow State University of Medicine and Dentistry, Delegatskaya Str. 20, Bldg. 1, Moscow 127473, Russian Federation

${ }^{2}$ Institute of General Pathology and Pathophysiology, Baltijskaya Str. 8, Moscow 125315, Russian Federation
\end{abstract}

The review analyzes mechanisms of gouty inflammation and resolution of acute inflammation in gout and shows how their understanding contributes to creation of new technologies for the treatment of gout. The first part of the review addresses crystal-induced inflammation in gout, which is associated with activation of the NLRP3 inflammasome in macrophages. The crystal-induced inflammation consists of two stages, 1) synthesis of inflammasome components and 2) inflammasome assembly. The review analyzes signals activating the synthesis of inflammasome components, which are generated by the interaction of MSU (monosodium urate crystals) and macrophages. Stages of inflammation initiation are described, including the synthesis of inflammasome components, pro-caspases and pro-IL-1 $\beta$. IL-1 $\beta$ is the main effector cytokine of gouty inflammation, which not only triggers the inflammatory response but also induces vasodilation, attraction of neutrophils to the place of crystal deposition, and even a greater potentiation of the acute inflammatory episode via the TLR-dependent activation of NF-KB (transcription factor). The role of soluble uric acid in the activation of NLRP3 inflammasomes is addressed. The main role in resolving acute gouty inflammation belongs to the same cells, macrophages and neutrophils, that contribute to the development of inflammation. The review focuses on signaling pathways switching the inflammatory response to inflammation resolution and termination, including the AMPK (AMP-activated kinase) signaling pathway, the TGF $\beta 1$, IL-10 and IL-1Ra anti-inflammatory cytokines, the protein annexin $A 1$ (AnxA1), and a1-antitrypsin (AAT). The authors described in detail the techniques for therapeutic suppression of inflammation in gout using inflammasome and IL-1 $\beta$ inhibitors. Studying the mechanisms of gouty inflammation and its 
resolution has resulted in development of methods for reprogramming immune cells and adaptive immunotherapy of gout. These methods have already shown outstanding therapeutic potential for patients with other diseases such as cancer.

Keywords: gout; inflammasome; neutrophils; macrophages; uric acid crystals; IL-1 $\beta$.

For citation: Malyshev I.Yu., Pihlak A.E., Budanova O.P. [Molecular and cell mechanisms of inflammation in gout]. Patogenez [Pathogenesis]. 2019; 17(4): 4-13 (in Russian).

DOI: $10.25557 / 2310-0435.2019 .04 .4-13$

For correspondence: Malyshev Igor Yurievich, e-mail: iymalyshev1@gmail.com

Funding: The review was supported by the Russian Foundation for Basic Research (RFBR) based on the results of a competitive selection of research projects as the winner of the YUMIF_t contest, the 2018 contest for basic research conducted jointly by the Russian Foundation for Basic Research and the Japan Foundation for Medical Research, Contract \# 18-515-57003\18 of 24.05.2018 Conflict of interest: The authors declare no conflict of interest.

Received: 11.04 .2019

\section{Основные принятые сокращения:}

АФК - активные формы кислорода; НПВП нестероидные противовоспалительные препараты; A1 (AnxA1) - белоканнексин;AAT - $\alpha 1$-антитрипсин; ASC Apoptosis-associated Speck-like protein containing a CARD (адапторный белок); CARD - Caspase activation and recruitment domains (домены активации и рекрутирования каспаз); FFA - свободные жирные кислоты с длинной цепью; IkB (IKK) киназа - комплекс энзима который включается при воспалении; IL-1 $\beta$ - интерлейкин $1 \beta$; IL-1R1 - рецептор интерлейкина 1; IRAK - interleukin-1 receptor-associated kinase (группа сигнальных киназ); MCC950 - диарилсульфонилмочевина-содержащее соединение; MSU - кристаллы урата мононатрия; MSR macrophage scavenger receptor, transcript variant SR-AI (Scavenger Receptors A) и MARCO (SR-A6), а также SR-B1 и CD36 (SR-B2) (макрофагальные рецепторы); MyD88 - адапторный белок; NET - neutrophil extracellular traps (внеклеточные нейтрофильные ловушки); NF-kB - фактор транскрипции; NLRP3 инфламмасома - инфламмасома, которая ответственна за активацию каспазы-1; TLR - лиганды Toll-подобных рецепторов; Ser/Thr (Nek) киназа - серин-треониновая киназа; TNF receptor-associated factor $\mathbf{6}-$ цитозольный адаптерный белок, относящийся к семейству факторов, связанных с рецептором TRAF; TRAF6 - фактор 6, ассоциированный с рецептором фактора некроза опухолей.

\section{Введение}

Подагра является одной из самых распространненных причин воспалительного артрита [1]. В России подагра выявляется у $0,1 \%$, а в США и Европе - у $2 \%$ жителей. Пик заболеваемости приходится на 50-60 лет. В этой возрастной группе подагрой болеют 4-6\%. [2]. Подагра развивается тогда, когда концентрация мочевой кислоты в крови начинает превышать 7 мг/л (гиперурикемия). При таких высоких концентрациях образуются кристаллы урата мононатрия (MSU). MSU взаимодействует с макрофагами и индуцирует воспаление в местах отложения кристаллов. Клинически подагра проявляется рецидивирующими острыми приступами воспаления суставов, образо- ванием подагрических узлов (тофусов), и, при отсутствии лечения - прогрессирующим разрушением суставов, образованием камней в почках и развитием почечной недостаточности [3].

В обзоре проанализированы механизмы подагрического воспаления и то, как их понимание способствует созданию новых технологий лечения подагры.

\section{Развитие острого воспаления при подагре: роль NF-kB, инфламмасом и IL-1b}

Кристалл-индуцированное воспаление при подагре связано с активацией инфламмасомы NLRP3 в макрофагах [4, 5]. Инфламмасома представляет собой цитозольный мультипротеиновый комплекс, который продуцирует воспалительные цитокины [6]. Активация инфламмасомы состоит из двух этапов: 1) синтез компонентов инфламмасомы; 2) сборка инфламмасомы. Какие сигналы активируют синтез компонентов инфламмасомы при подагре, до конца не ясны. Возможно, это лиганды Toll-подобных рецепторов (TLR) [7], которые активируют фактор транскрипции NF-kB. Сигналы активации сборки инфламмасомы генерируются при взаимодействии кристаллов MSU с макрофагами [4]. После сборки инфламмасома вместе с адапторными белками и про-каспазой-1 образует молекулярную платфому по производству воспалительного цитокина IL-1 $\beta$ и мембраных каналов для вы-

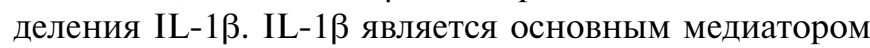
подагрического воспаления и фактором разрушения хрящевой ткани сустава. Кроме того, IL-1 $\beta$ может активировать NF-kB и синтез компонентов инфламмасомы, и таким образом формировать положительную обратную связь при остром подагрическом воспалении.

\section{NF-kB - триггер синтеза компонентов инфоламмасомы NLRP3}

На первом этапе инициации воспаления при подагре происходит подготовка макрофагов к сборке инфламмасом - синтез компонентов инфламмасомы, про-каспаз и про-IL-1 $\beta$ [8]. Ключевую роль в этом процессе, вероятно, играет TLR-зависимая активация NF- $x \mathrm{~B}$ (рис. 1). 
Это подтверждают эксперименты на мышах с дефицитом TLR2 или TLR4, у которых иммуные клетки слабее реагировали на кристалы MSU, по сравнению с клетками нормальных мышей [7]. Предполагается, что лигандами TLR могли бы быть или липополисахариды, или кристалы MSU. Однако четких доказательств о том, что кристаллы MSU могут непосредственно связываться с TLR, не было получено.

Предположение о других возможных лигандах TLR появилось, когда обнаружили, что у пациентов с подагрой и у мышей, которым вводили кристаллы MSU, вырабатывается много эндогенных лигандов TLR4 - белков S100A8 и S100A9, а генетическая делеция S100A9 снижала ответы иммуных клеток на кристаллы MSU [9]. Возможно, что S100A8 и S100A9 при взаимодействии с TLR активируют NF- $x$ B и инициируют синтез компонентов инфламмасомы.

Другими лигандами TLR, запускающими активацию NF- $x$ B и синтез компонентов инфламмасомы, могут быть свободные жирные кислоты с длинной цепью (FFA). В мышиной модели подагры артрит наблюдался только при совместном введениии FFA и кристаллов MSU, тогда как по отдельности эти компоненты не вызывали воспаление [10].

Таким образом, TLR/NF- $x$ B-зависимый путь является основным кандидатом на роль активатора продукции компонентов инфламмасомы. Для активации инфламмасомы и синтеза IL-1 $\beta$ необходимы специ- фические сигналы, которые генерируются при взаимодействии MSU с макрофагами.

\section{Инфламмасома NLRP3 - молекулярная платформа кристалл-индуцированной активации воспаления nрu nодагре}

Впервые взаимодействие MSU с макрофагами в форме фагоцитоза наблюдали с помощью электронной микроскопии почти 50 лет назад [11]. Обычно фагоцитоз начинается с распознавания частиц или микробов с помощью разных рецепторов на поверхности макрофагов [12]. Общей свойством органических частиц, таких как бактерии или апоптотические клетки, и неорганических частиц, таких как кристалы MSU, является наличие отрицательно заряженной поверхности [13]. Наличие отрицательного заряда благоприятствует связыванию частиц с макрофагальными рецепторами SR-A1 (MSR) и MARCO (SR-A6), а также SR-B1 и CD36 (SR-B2) [12]. Однако, в отличие от органических частиц, поверхность кристалла MSU однородна. Эта особенность препятствует связыванию кристаллов с рецепторами типа SR-A1 или SR-B1 [14]. Фагоцитарные рецепторы для кристаллов MSU пока не обнаружены. Поэтому для кристаллов MSU была предложена гипотеза рецептор независимого фагоцитоза [15]. Гипотеза предполагает, что кристаллы MSU связываются с холестеринами плазматической мембраны, и это взаимодействие инициирует поглощение кристаллов. Слабое

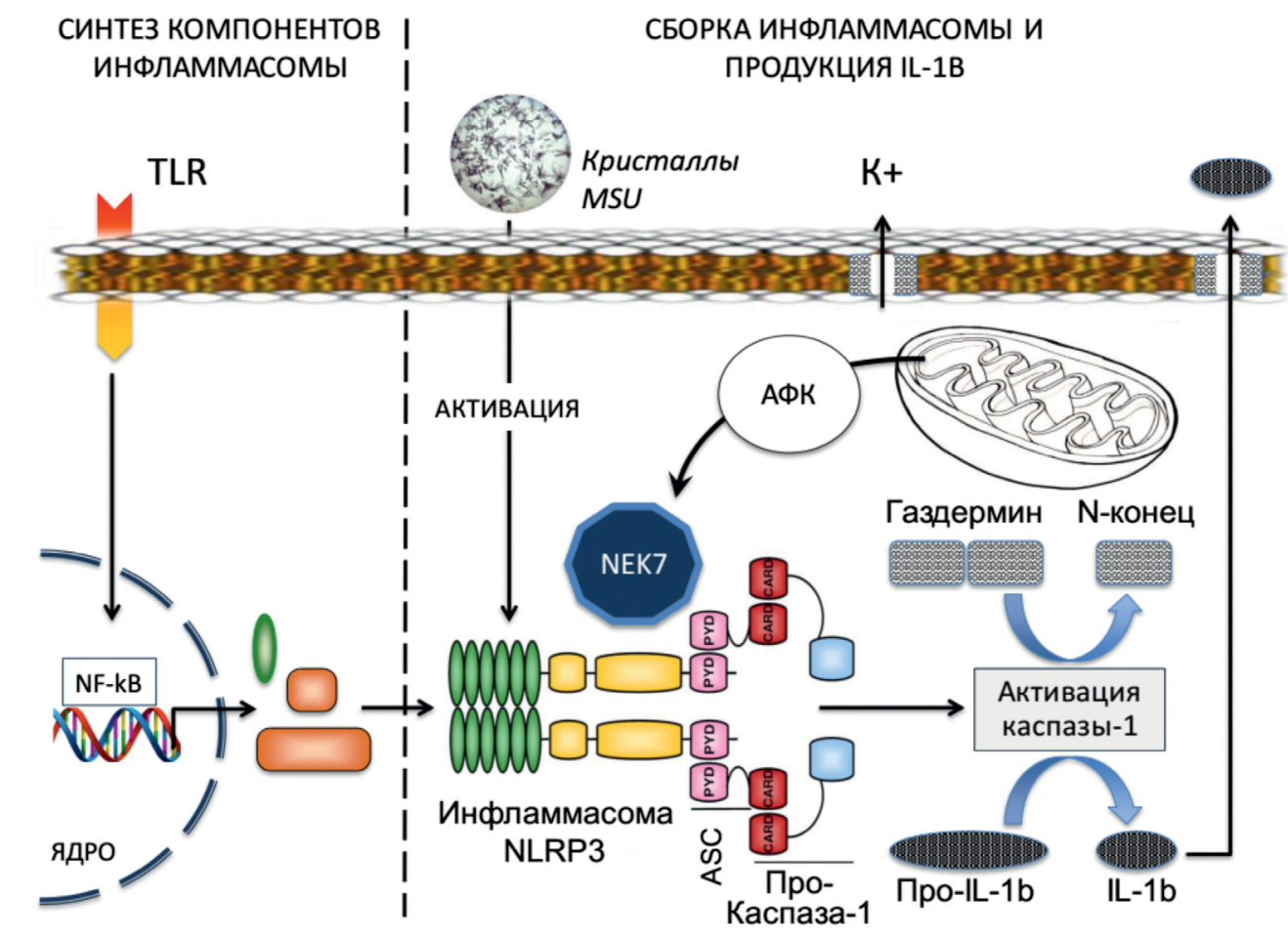

Рис. 1. Активация инфламмасомы NLRP3 состоит из двух этапов: 1) синтез компонентов инфламмасомы; 2) сборка и активация инфламмасомы при действии кристаллов MSU на макрофаги. Рисунок является результатом модификации и адаптации рисунка из обзора А.К. Sо and F. Martinon [5]. 
место гипотезы в том, что она не объясняет, почему кристаллы связываются с макрофагами/фагоцитами, тогда как холестерин имеется в мембране всех типов клеток.

Однако точный механизм и рецепторы распознавания кристаллов MSU макрофагами до конца не известны и их еще предстоит обнаружить [16].

Взаимодействие кристаллов MSU с мембраной макрофагов, или когда они поглощаются макрофагами, генерирует внутриклеточные сигналы активации сборки инфламасоммы [5, 6, 16] (рис. 1). Первая реакция макрофагов на кристаллы MSU проявляется выходом калия через ионные каналы [17] и высвобождением активных форм кислорода (АФК) из митохондрий [18]. Затем NIMA-связанная Ser/Thr (Nek) киназа (Nek7) катализирует олигомеризацию компонентов NLRP3 и сборку инфламмасомы [19]. После этого инфламмасома привлекает адапторный белок ASC (Apoptosisassociated Speck-like protein containing a CARD, CARD - домен, активирующий каспазу), который формирует прионоподобные филаменты [20]. К этим филаментам присоединяются про-каспазы-1, что приводит к аутопротеолитической активации каспазы-1. Активная каспаза-1 расщепляет про-IL-1 $\beta$ и про-IL-18 до биологически активных IL-1 $\beta$ и IL-18. Каспаза-1 также расщепляет газдермин Д с образованием домена $\mathrm{N}$-концевого участка. Эти домены олигомеризуется на плазматической мембране и образуют пироптотические поры [21]. Через эти поры высвобождаются медиаторы воспаления, включая IL-1 $\beta$ [5].

Образование пор может привести к гибели клетки, которая обозначается термином пироптоз [22]. Пироптоз, вызванный воспалительной каспазой-1 отличается от гибели клеток, вызванной апоптотическими каспазами, тем, что сопровождается высвобождением содержимого клеток вместе с провоспалительными медиаторами. Таким образом, пироптоз может ещё больше усилить выброс IL-1 $\beta$ и воспаление.

Кроме кристаллов MSU, активацию инфламмасомы NLRP3 может запускать растворимая мочевая кислота [23]. Хотя не исключено, что эту активацию могут вызывать необнаруживаемые микрокристаллы мочевой кислоты, или кристаллы, которые образуются в макрофагах после поглощения растворимой мочевой кислоты. Эти данные указывают на то, что мочевая кислота, высвобождаемая из умирающих клеток, может вызывать воспаление без отложения кристаллов. В результате может сформироваться порочный патологический круг: мочевая кислота активирует инфламмасомы, инфламмасомы инициируют воспаление и пироптотическую гибель клетки, а гибель клетки приводит к высвобождению мочевой кислоты, которая может активировать инфламмасомы в других макрофагах.

Мочевая кислота также может стимулировать продукцию IL-1 $\beta$ и IL-6 без вовлечения инфламмасом, через механизм эпигенетической модификации гистонов (метилирование) [24].
Активация инфламмасомы является основным механизмом продукции IL-1 $\beta$ при подагре. Однако другие протеазы также могут способствовать продукции этого цитокина [25]. В нейтрофилах в отсутствие инфламмасомы сериновые протеазы протеиназа-3, нейтрофильная эластаза и катепсин $\mathrm{G}$ могут расщеплять предшественники до IL-1 $\beta$ и IL-18 [25]. Некоторые металлопротеиназы и гранзим А также могут протеолитически активировать образование IL-1 $\beta[26,27]$. Не исключено, что вклад инфламмасома-независимых механизмов продукции IL-1 $\beta$ увеличивается после привлечения нейтрофилов, или когда белки инфламмасомы отсутствуют или ингибируются.

\section{IL-1b- основной эффректорный цитокин подагрического воспаления}

При подагре IL-1ß запускает не только воспалительный ответ, но и вызывает вазодилатацию сосудов, привлечение нейтрофилов к месту отложения кристаллов и ешё большее усиление острого воспалительного эпизода [28]. Устойчивая чрезмерная секреция IL-1 $\beta$ при подагре может стимулировать выработку ферментов, разрушающих костную и хрящевую ткани [29]. Действуя на центр регуляции температуры в гипоталамусе, IL-1 $\beta$ может вызвать лихорадку [30]. Таким образом, IL-1 $\beta$ является ключевым драйвером подагрического воспаления и его осложнений.

IL-1 $\beta$ продуцируется в основном макрофагами. После выделения IL-1 $\beta$ может связываться со своим рецептором IL-1R1 на разных типах клеток: лейкоцитах, эндотелиальных и синовиальных клетках [31]. Когда IL-1 $\beta$ связывается IL-1R1, к цитоплазматической части рецептора с помощью вспомогательного белка рецептора IL-1 (IL-1RAcP) присоединяется адапторный белок MyD88. Дальше к рецептору присоединяются киназы IRAK и фактор 6, связанный с рецептором TNF (TRAF6). После этого собирается комплекс из I $x$ B киназ (IKK), который фосфсорилирует и, благодаря этому, деградирует ингибитор NF- $x$ B - I $x$ B. Активный NF- $x$ B, с одной стороны, стимулирует транскрипцию цитокинов и хемокинов, которые усиливают IL-1 $\beta$ опосредованное воспаление, а с другой - активирует продукцию компонентов инфламмасомы, которая продуцирует IL-1ß. Таким образом происходит каскадное усиление подагрического воспаления и формирование провоспалительной петли положительной обратной связи.

Клиническая значимость IL-1b подтверждается хорошими результатами применения анти-IL-1 $\beta$ моноклокального антитела канакинумаб и антагониста рецептора IL-1 (IL-1Ra) анакинра при лечении подагры [32].

При подагре спектр продуцируемых макрофагами цитокинов дополняют IL-1 $\alpha$ и IL-8. Оба цитокина, вероятно, участвуют в привлечение нейтрофилов в очаг подагрического воспаления [33]. Роль нейтрофилов в кристалл-индуцированном воспалении при подагре хорошо описана в работе Popa-Nita et al. [34]. 
Разрешение кристалл-индуцированного воспаления при подагре: роль макрофагов и нейтрофилов

В разрешении острого воспаления при подагре основную роль играют те же клетки, что и в развитии классической воспалительной реакции: макрофаги и нейтрофилы.

\section{Макрофаги и антивоспалительные факторы АМРК, TGF- $\beta 1$, аннексин A1 и а1-антитрипсин}

К числу сигнальных путей, которые переключают воспалительный ответ на разрешение и завершение воспаления, относится АМРК (АМР-активируемая киназа) зависимый путь [35]. Активация этого пути в макрофагах приводит к ингибированию кристалл-индуцированного воспаления, как in vitro у макрофагов, так и in vivo у мышей [36]. Одним из активаторов АМРК является колхицин [36]. Это позволяет предположить, что способность колхицина ингибировать MSU-индуцированную секрецию IL-1 $\beta$ [4] опосредована его эффектами на АМРК.

Антивоспалительные цитокины, выделяемые макрофагами, дополнительно способствуют разрешению острого воспаления. Так, у пациентов с подагрическим артритом повышение концентраций TGF $\beta 1$, IL10 и IL-1Ra в синовиальной жидкости коррелировало со спонтанным разрешением подагрического артрита [37], а добавление экзогенного TGF- $\beta 1$ уменьшало воспаление в моделях подагры на животных [38].

Galvao с соавторами установили, что в разрешение воспаления при подагре также вовлечен белок аннексин A1 (AnxA1) [39]. Исследователи показали, что разрешение воспаления сопровождалось увеличением экспрессии AnxA1, а блокада AnxA1 или его рецепторов предотвращали спонтанное разрешение подагры. C другой стороны, введение мышам AnxA1-активного $\mathrm{N}$-концевого пептида приводило к снижению притока нейтрофилов, продукции IL-1 $\beta$ и CXCL1 в воспаленном суставе.

Предположение о роли $\alpha 1$-антитрипсина (ААТ) в разрешении воспаления возникло после обнаружения обратной корреляции сезонных колебаний концентрации ААТ с продукцией провоспалительных цитокинов у пациентов с подагрой [40]. Зимой, когда концентрации циркулирующего ААТ максимальны, наблюдается наименьшее количество приступов подагры, а в весенние и летние месяцы, когда концентрации ААТ минимальны, подагрическое воспаление и осложнения развиваются наиболее часто [41]. Антивоспалительный эффект ААТ определяется его способностью ингибировать сериновые протеазы, которые обеспечивают продукцию IL-1 $\beta$ при действии кристаллов MSU [42].

\section{Нейтрофилы - ловушка \\ провоспалительных медиаторов}

Антивоспалительная роль нейтрофилов обусловлена их способностью формировать внеклеточные нейтрофильные ловушки (neutrophil extracellular traps, NET).
Формирование NET начинается при высоких концентрациях нейтрофилов (более $10 \times 10^{6}$ кл. / мл) с образования агрегатов, которые содержат клеточный дебрис и нейтрофильные протеазы [43]. Формирование NET зависит от АФК и вовлекает RIPK1-RIPK3-MLKL сигнальные пути [44]. NET может расщеплять провоспалительные цитокины и хемокины и обеспечивать спонтанное прекращение воспаление в суставе в течение 3 дней, тогда как нарушение образования NET приводит к тяжелому и стойкому воспалению [43].

Таким образом, нейтрофилы, как и макрофаги, играют двойную роль в подагрическом воспалении: 1) усиливают воспаление на начальных стадиях; 2) обеспечивают его разрешение на более поздних.

\section{Терапевтическое блокирование воспаления при подагре:} ингибиторы инфламмасомы и ингибиторы IL-1 $\beta$

Для лечения подагры используют препараты, снижающие уровень мочевой кислоты, и препараты, уменьшающие воспаление. В последней категории нестероидные противовоспалительные препараты (НПВП), колхицин и глюкокортикоиды демонстрируют хорошую эффективность для уменьшения боли и воспаления при остром приступе. Улучшение понимания биологии подагрического воспаления открыло путь к новым еще более эффективным терапевтическим технологиям и препаратам. Это ингибиторы NLRP3 инфламмасомы, ингибиторы образования IL-1 $\beta$, ингибиторы IL-1 $\beta$ и его рецептора.

\section{Ингибиторы сборки NLRP3 инфламмасомы}

Инфламмасома NLRP3 является ключевым компонентом кристалл-индуцированного воспаления. Поэтому ожидания терапевтического эффекта ингибиторов сборки инфламмасомы вполне оправдались. После раскрытия роли продукции АФК в активации инфламмасомы было показано, что соединения, которые ингибируют выработку АФК, действительно обладают определенным лечебным эффектом. Галлат эпигаллокатехина, антиоксидант, содержащийся в зелёном чае, ингибирует инфильтрацию нейтрофилов и секрецию IL-1 $\beta$ в мышиной модели кристаллического перитонита [45]. Морин, природный флавонол, ослабляет, вызванное кристаллами MSU воспаление у макрофагов мышей [46]. Гастропротекторный препарат ребамипид подавляет опосредованную кристаллами MSU активацию и высвобождение IL-1 $\beta$ на THP-1 клеточной линии человека [47]. Ингибиторы ксантиноксидазы, которые непосредственно влияют на выработку АФК, ингибируют MSU-индуцированную активацию инфламмасомы [48].

Ингибирование продукции АФК представляет собой довольно неспецифический подход, который может иметь нежелательные последствия. Поэтому поиск специфических ингибиторов NLRP3 инфламмасомы представлял собой более желанную цель для тех, кто разрабатывал новые методы лечения подагры. Таким 
препаратом оказался МСС950, диарилсульфонилмочевина-содержащее соединение [49, 50]. МСС950 специфически блокирует индуцированную NLRP3, олигомеризацию ASC в макрофагах мышей и человека и препятствует действию разных активаторов NLRP3, в том числе кристаллов MSU [51].

$\beta$-Гидроксибутират, который блокирует сборку NLRP3, также снижал кристалл-индуцированное воспаление [51]. $\beta$-Гидроксибутират вырабатывается в печени млекопитающих при недостатке питательных веществ. Это объясняет, почему голодание ослабляет активацию каспазы-1 и секрецию IL-1 у мышей на диете с ограниченой калорийностью [51].

\section{Ингибиторы IL-1 $\beta$ и IL-1R}

Значительные усилия были предприняты для поиска специфических ингибиторов каспазы-1, фермента необходимого для образования IL-1ß. VX-765 является одним из этих ингибиторов [52]. VX-765 уменьшал тяжесть и прогрессирование артрита на мышиной модели [53]. Другой ингибитор каспазы-1, пралнаказан, также снижал продукцию IL-1 $\beta$ и повреждение хряща у мышей с хроническим деструктивным воспалением суставов [54].

Ингибиторы сериновой протеазы также могут представлять интерес для лечения приступов подагры. Как уже указано выше, AАТ подавляет выработку IL$1 \beta$ и воспаление при подагре [40, 42].

Продуктивными оказались попытки лечить подагрическое воспаление с помощью блокирования IL-1 $\beta$ или его рецептора антителами [32]. К препаратам с таким действием относятся канакинумаб - специфический ингибитор IL-1 $\beta$, и анакинра - ингибитор связывание IL- $1 \alpha$ и IL- $1 \beta$ с IL-1R1.

Ингибирование IL-1 может ослабить острые симптомы подагры даже у пациентов, которым обычное лечение (НПВП, колхицин или глюкокортикоиды) не помогло или противопоказано. Клинические испытания канакинумаба и анакинры показали быстрое обезболивание почти у всех пациентов с острым приступом подагры [32]. Однако, при использовании анти-IL-1 препаратов необходимо учитывать возможность инфекционных осложнений.

\section{Заключение.}

\section{Оставшиеся вопросы и перспективы}

Изучение старой болезни подагры дало нам новое, лучшее понимание путей воспаления. Однако несколько важных вопросов до сих пор остаются без ответа. Все ещё неясен конкретный механизм активации NLRP3 при действии кристаллов MSU. Пока нет понимания, как размер кристаллов MSU может влиять на иммунные реакции. До сих пор плохо изучены каспаза-1 независимые механизмы продукции IL-1b, включая то, какие протеазы задействованы, и что вызывает их активацию. Остаются непонятными механизмы инициации приступов подагры у пациен- тов с постоянным отложенем кристаллов MSU. Наконец, чем обусловлена цикличность приступов подагры - тем что расходуются инфламмасомы в результате гибели клеток и нужно время для привлечения новых иммуных клеток и время для синтеза компонентов инфламмасомы, или другими событиями.

Изучение механизмов подагрического воспаления подсказало большое количество потенциальных терапевтических мишеней для лечения подагры. Это ионные каналы выхода калия, Nek7, адаптерный белок ASC, каспаза-1, пироптотические поры, NET. Однако пока нет методов лечения, которые использовали бы эти мишени, соответственно появляется сразу несколько преспективных областей для разработки антиподагрических технологий и лекарств.

Макрофаги и нейтрофилы играют ключевую роль, как в развитии воспаления, так и в его разрешении [55]. А это значит, что пришло время для разработки методов репрограммирования иммунных клеток и адаптивной иммунотерапии подагры, методов, которые при других заболеваниях, таких как рак, уже показали выдающиеся возможности лечения больных. Решение оставшихся вопросов несёт в себе огромный потенциал для новых открытий и разработки технологий терапии, которые могут сделать профилактику и лечение подагры, и, возможно, других воспалительных заболеваниях, более эффективной.

\section{Список литературы}

1. Kuo C.F., Grainge M.J., Zhang W., Doherty M. Global epidemiology of gout: prevalence, incidence and risk factors. Nat. Rev. Rheumatol. 2015; 11(11): 649-662. DOI:10.1038/nrrheum.2015.91

2. Насонов С.Л. Ревматология: кинические рекомендации. Москва: ГЭОТАР-Медиа, 2008: 112-119.

3. Dalbeth N., Merriman T.R., Stamp L.K. Gout. Lancet. 2016; 388(10055): 2039-2052. DOI: 10.1016/S0140-6736(16)00346-9

4. Martinon F., Petrilli V., Mayor A., Tardivel A., Tschopp J. Gout-associated uric acid crystals activate the NLRP3 inflammasome. $\mathrm{Na}$ ture. 2006; 440(7081): 237-224. DOI: 10.1038/nature04516

5. So A.K., Martinon F. Inflammation in gout: mechanisms and therapeutic targets. Nat. Rev. Rheumatol. 2017; 13(11): 639-647. DOI:10.1038/nrrheum.2017.155

6. Broz P., Dixit V.M. Inflammasomes: mechanism of assembly, regulation and signalling. Nat. Rev. Immunol. 2016; 16(7): 407-420. DOI: 10.1038/nri.2016.58

7. Liu-Bryan R., Scott P., Sydlaske A., Rose D.M., Terkeltaub R. Innate immunity conferred by Toll-like receptors 2 and 4 and myeloid differentiation factor 88 expression is pivotal to monosodium urate monohydrate crystal-induced inflammation. Arthritis Rheum. 2005; 52(9), 2936-2946. DOI: 10.1002/art.21238

8. Burns K., Martinon F., Tschopp J. New insights into the mechanism of IL-1ß maturation. Curr. Opin. Immunol. 2003; 15(1): 26-30. DOI: 10.1016/s0952-7915(02)00017-1

9. Holzinger D., Nippe N., Vogl T., Marketon K., Mysore V., Weinhage T., Dalbeth N., Pool B., Merriman T., Baeten D., Ives A., Busso N., Foell D., Bas S., Gabay C., Roth J. Myeloid-related proteins 8 and 14 contribute to monosodium urate monohydrate crystal-induced inflammation in gout. Arthritis Rheum. 2014; 66(5): 1327-1339. DOI: 10.1002/art.38369

10. Joosten L.A., Netea M.G., Mylona E., Koenders M.I., Malireddi R.K., Oosting M., Stienstra R., van de Veerdonk F.L., Stalenhoef A.F., Giamarellos-Bourboulis E.J., Kanneganti T.D., van der Meer J.W. Engagement of fatty acids with Toll-like receptor 2 drives interleukinlbeta production via the $\mathrm{ASC} /$ caspase 1 pathway in monosodium urate monohydrate crystal-induced gouty arthritis. Arthritis Rheum. 2010; 62(11): 3237-3248. DOI: 10.1002/art.27667 
11. Schumacher H.R., Phelps P. Sequential changes in human polymorphonuclear leukocytes after urate crystal phagocytosis. An electron microscopic study. Arthritis Rheum. 1971; 14(4): 513-526. DOI: 10.1002/art.1780140411

12. PrabhuDas M.R., Baldwin C.L., Bollyky P.L., Bowdish D.M.E., Drickamer K., Febbraio M., Herz J., Kobzik L., Krieger M., Loike J., McVicker B., Means T.K., Moestrup S.K., Post S.R., Sawamura T., Silverstein S., Speth R.C., Telfer J.C., Thiele G.M., Wang X.Y., Wright S.D., El Khoury J. A consensus definitive classification of scavenger receptors and their roles in health and disease. J. Immunol. 2017; 198(10): 3775-3789. DOI: 10.4049/jimmunol.1700373

13. Shi Y., Mucsi A.D., Ng G. Monosodium urate crystals in inflammation and immunity. Immunol Rev. 2010; 233(1): 203-217. DOI: 10.1111/j.0105-2896.2009.00851.x

14. Tsugita M., Morimoto N., Tashiro M., Kinoshita K., Nakayama M. SR-B1 is asilica receptor that mediates canonical inflammasome activation. Cell Rep. 2017; 18(5): 1298-1311. DOI: 10.1016/j.celrep.2017.01.004

15. Ng G., Sharma K., Ward S.M., Desrosiers M.D., Stephens L.A. Schoel W.M., Li T., Lowell C.A., Ling C.C., Amrein M.W., Shi Y. Receptor-independent, direct membrane binding leads to cell-surfacelipid sorting and Syk kinase activation in dendritic cells. Immunity. 2008; 29(5): 807-818. DOI: 10.1016/j.immuni.2008.09.01

16. Nakayama M. Macrophage Recognition of Crystals and Nanoparticles. Front. Immunol. 2018; 9: 103. DOI: 10.3389/fimmu.2018.00103

17. Yaron J.R., Gangaraju S., Rao M.Y., Kong X., Zhang L., Su F., Tian Y., Glenn H.L., Meldrum D.R. $\mathrm{K}(+)$ regulates $\mathrm{Ca}(2+)$ to drive inflammasome signaling: dynamic visualization of ion flux in live cells. Cell Death Dis. 2015; 6: e1954. DOI: 10.1038/cddis.2015.277

18. Amaral F.A., Costa V.V., Tavares L.D., Sachs D., Coelho F.M., Fagundes C.T., Soriani F.M., Silveira T.N., Cunha L.D., Zamboni D.S., Quesniaux V., Peres R.S., Cunha T.M., Cunha F.Q., Ryffel B., Souza D.G., Teixeira M.M. NLRP3 inflammasome-mediated neutrophil recruitment and hypernociception depend on leukotriene B4 in a murine model of gout. Arthritis Rheum. 2012; 64(2): 474-484. DOI: $10.1002 /$ art. 33355

19. Shi H., Wang Y., Li X., Zhan X., Tang M., Fina M., Su L., Pratt D. Bu C.H., Hildebrand S., Lyon S., Scott L., Quan J., Sun Q., Russell J., Arnett S., Jurek P., Chen D., Kravchenko V.V., Mathison J.C., Moresco E.M., Monson N.L., Ulevitch R.J., Beutler B. NLRP3 activation and mitosis are mutually exclusive events coordinated by NEK7, a new inflammasome component. Nat. Immunol. 2016; 17(3): 250-258. DOI: $10.1038 /$ ni. 3333

20. Cai X., Chen J., Xu H., Liu S., Jiang Q.X., Halfmann R., Chen Z.J. Prion-like polymerization underlies signal transduction in antiviral immune defense and inflammasome activation. Cell. 2014; 156(6): 1207-1222. DOI: 10.1016/j.cell.2014.01.063

21. Aglietti R.A., Dueber E.C. Recent insights into the molecular mechanisms underlying pyroptosis and gasdermin family functions. Trends Immunol. 2017; 38(4): 261-271. DOI: 10.1016/j.it.2017.01.003

22. Kayagaki N., Stowe I.B., Lee B.L., O'Rourke K., Anderson K., Warming S., Cuellar T., Haley B., Roose-Girma M., Phung Q.T., Liu P.S., Lill J.R., Li H., Wu J., Kummerfeld S., Zhang J., Lee W.P., Snipas S.J., Salvesen G.S., Morris L.X., Fitzgerald L., Zhang Y., Bertram E.M., Goodnow C.C., Dixit V.M. Caspase-11 cleaves gasdermin D for non-canonical inflammasome signalling. Nature.2015; 526(7575): 666-671. DOI: $10.1038 /$ nature 15541

23. Braga T.T., Forni M.F., Correa-Costa M., Ramos R.N., Barbuto J.A., Branco P., Castoldi A., Hiyane M.I., Davanso M.R., Latz E., Franklin B.S., Kowaltowski A.J., Camara N.O. Soluble uric acid activates the NLRP3 inflammasome. Sci. Rep. 2017; 7: 39884. DOI: 10.1038/srep39884

24. Crisan T.O., Cleophas M.C., Oosting M., Lemmers H., Toenhake-Dijkstra H., Netea M.G., Jansen T.L., Joosten L.A. Soluble uric acid primes TLR-induced proinflammatory cytokine production by human primary cells via inhibition of IL-1Ra. Ann. Rheum. Dis. 2016; 75(4): 755-762. DOI: 10.1136/annrheumdis-2014-206564

25. Netea M.G., van de Veerdonk F.L., van der Meer J.W., Dinarello C.A., Joosten L.A. Inflammasome-independent regulation of IL-1-family cytokines. Аnпи. Rev. Immunol. 2015; 33: 49-77. DOI: 10.1146/annurev-immunol-032414-112306

26. Echtermeyer F., Bertrand J., Dreier R., Meinecke I., Neugebauer K., Fuerst M., Lee Y.J., Song Y.W., Herzog C., Theilmeier G., Pap T. Syndecan-4 regulates ADAMTS-5 activation and cartilage breakdown in osteoarthritis. Nat. Med. 2009; 15(9): 1072-1076. DOI: $10.1038 / \mathrm{nm} .1998$
27. Irmler M., Hertig S., MacDonald H.R., Sadoul R., Becherer J.D., Proudfoot A., Solari R., Tschopp J. Granzyme A is an interleukin 1ß-converting enzyme. J. Exp. Med. 1995; 181(5): 1917-1922. DOI: 10.1084/jem.181.5.1917

28. So A., Dumusc A., Nasi S. The role of IL-1 in gout: from bench to bedside. Rheumatology (Oxford). 2018; 57(1): 12-19. DOI: 10.1093/ rheumatology/kex449

29. Schlesinger N., Thiele R.G. The pathogenesis of bone erosions in gouty arthritis. Ann. Rheum. Dis. 2010; 69(11): 1907-1912. DOI: 10.1136/ard.2010.128454

30. Dinarello C.A. Infection, fever, and exogenous and endogenous pyrogens: some concepts have changed. J. Endotoxin Res. 2004; 10(4): 201-222. DOI: $10.1177 / 09680519040100040301$

31. Dinarello C.A. Immunological and inflammatory functions of the interleukin-1 family. Annu. Rev. Immunol. 2009; 27: 519-550. DOI 10.1146/annurev.immunol.021908.132612

32. Dumusc A., So A. Interleukin-1 as a therapeutic target in gout Curr. Opin. Rheumatol. 2015; 27(2): 156-163. DOI: 10.1097 BOR.0000000000000143

33. Kienhorst L.B., van Lochem E., Kievit W., Dalbeth N., Merriman M.E., Phipps-Green A., Loof A., van Heerde W., Vermeulen S., Stamp L.K., van Koolwijk E., de Graaf J., Holzinger D., Roth J., Janssens H.J., Merriman T.R., Broen J.C., Janssen M., Radstake T.R. Gout is a chronic inflammatory disease in which high levels of interleukin-8 (CXCL8), myeloid-related protein 8/myeloid-related protein 14 complex, and an altered proteome are associated with diabetes mellitus and cardiovascular disease. Arthritis Rheumatol. 2015; 67(12): 3303-3313. DOI: 10.1002/art.39318

34. Popa-Nita O., Naccache P.H. Crystal-induced neutrophil activation. Immunol. Cell Biol. 2010; 88(1): 32-40. DOI: 10.1038/icb.2009.98

35. Carling D. AMPK signalling in health and disease. Curr. Opin. Cell Biol. 2017; 45: 31-37. DOI: 10.1016 / j.ceb.2017.01.005

36. Wang Y., Viollet B., Terkeltaub R., Liu-Bryan R. AMP-activated protein kinase suppresses urate crystal-induced inflammation and transduces colchicine effects in macrophages. Ann. Rheum. Dis. 2016; 75(1): 286-294. DOI: 10.1136/annrheumdis-2014-206074

37. Chen Y.H., Hsieh S.C., Chen W.Y., Li K.J., Wu C.H., Wu P.C., Tsai C.Y., Yu C.L. Spontaneous resolution of acute gouty arthritis is associated with rapid induction of the anti-inflammatory factors TGF $\beta 1$, IL-10 and soluble TNF receptors and the intracellular cytokine negative regulators CIS and SOCS3. Ann. Rheum. Dis. 2011; 70(9): 1655-1663. DOI: $10.1136 /$ ard.2010.145821

38. Lioté F., Prudhommeaux F., Schiltz C., Champy R., Herbelin A. Ortiz-Bravo E., Bardin T. Inhibition and prevention of monosodium urate monohydrate crystal-induced acute inflammation in vivo by transforming growth factor $\beta 1$. Arthritis Rheum. 1996; 39(7): 11921198. DOI: $10.1002 /$ art.1780390718

39. Galvão I, Vago J.P., Barroso L.C., Tavares L.P., Queiroz-Junior C.M., Costa V.V., Carneiro F.S., Ferreira T.P., Silva P.M., Amaral F.A., Sousa L.P., Teixeira M.M. Annexin A1 promotes timely resolution of inflammation in murine gout. Eur. J. Immunol. 2017; 47(3): 585-596. DOI: 10.1002/eji.201646551

40. Ter Horst R., Jaeger M., Smeekens S.P., Oosting M., Swertz M.A., Li Y., Kumar V., Diavatopoulos D.A., Jansen A.F.M., Lemmers H., Toenhake-Dijkstra H., van Herwaarden A.E., Janssen M., van der Molen R.G., Joosten I., Sweep F.C.G.J., Smit J.W., Netea-Maier R.T., Koenders M.M.J.F., Xavier R.J., van der Meer J.W.M., Dinarello C.A., Pavelka N., Wijmenga C., Notebaart R.A., Joosten L.A.B., Netea M.G.. Host and environmental factors influencing individual human cytokine responses. Cell. 2016; 167(4): 1111-1124. e13. DOI: 10.1016/j.cell.2016.10.018

41. Elliot A.J., Cross K.W., Fleming D.M. Seasonality and trends in the incidence and prevalence of gout in England and Wales 19942007. Ann. Rheum. Dis. 2009; 68(11): 1728-1733. DOI: 10.1136/ ard.2008.096693

42. Joosten L.A., Crisan T.O., Azam T., Cleophas M.C., Koenders M.I., van de Veerdonk F.L., Netea M.G., Kim S., Dinarello C.A. Alpha-1-anti-trypsin-Fc fusion protein ameliorates gouty arthritis by reducing release and extracellular processing of IL-1 $\beta$ and by the induction of endogenous IL-1Ra. Ann. Rheum. Dis. 2016; 75(6): 12191227. DOI: $10.1136 /$ annrheumdis-2014-206966

43. Schauer C., Janko C., Munoz L.E., Zhao Y., Kienhöfer D., Frey B., Lell M., Manger B., Rech J., Naschberger E., Holmdahl R., Krenn V., Harrer T., Jeremic I., Bilyy R., Schett G., Hoffmann M., Herrmann M. Aggregated neutrophil extracellular traps limit inflamma- 
tion by degrading cytokines and chemokines. Nat. Med. 2014; 20(5): 511-517. DOI: $10.1038 / \mathrm{nm} .3547$

44. Desai J., Kumar S.V., Mulay S.R., Konrad L., Romoli S., Schauer C., Herrmann M., Bilyy R., Müller S., Popper B., Nakazawa D., Weidenbusch M., Thomasova D., Krautwald S., Linkermann A., Anders H.J. PMA and crystal-induced neutrophil extracellular trap formation involves RIPK1-RIPK3-MLKL signaling. Eur. J. Immunol. 2016; 46(1): 223-229. DOI: 10.1002/eji.201545605

45. Jhang J.J., Lu C.C., Yen G.C. Epigallocatechin gallate inhibits urate crystals-induced peritoneal inflammation in C57BL/6 mice. Mol. Nutr. Food Res. 2016; 60(10): 2297-2303. DOI: 10.1002/mnfr.201600106

46. Dhanasekar C., Kalaiselvan S., Rasool M. Morin, a bioflavonoid suppresses monosodium urate crystalinduced inflammatory immune response in RAW 264.7 macrophages through the inhibition of inflammatory mediators, intracellular ROS levels and NF- $x \mathrm{~B}$ activation. PLoS ONE. 2015; 10(12): e0145093. DOI: 10.1371/journal.pone.0145093

47. Kim S.K., Choe J.Y., Park K.Y. Rebamipide suppresses monosodium urate crystal-induced interleukin-1 $\beta$ production through regulation of oxidative stress and caspase- 1 in THP-1 cells. Inflammation. 2016; 39(1): 473-482. DOI: 10.1007/s10753-015-0271-5

48. Ives A., Nomura J., Martinon F., Roger T., LeRoy D., Miner J.N., Simon G., Busso N., So A. Xanthine oxidoreductase regulates macrophage IL-1 $\beta$ secretion upon NLRP3 inflammasome activation. Nat. Commun. 2015; 6: 6555. DOI: 10.1038 / ncomms7555

49. Perregaux D.G., McNiff P., Laliberte R., Hawryluk N., Peurano H., Stam E., Eggler J., Griffiths R., Dombroski M.A., Gabel C.A. Identification and characterization of a novel class of interleukin-1 post-translational processing inhibitors. J. Pharmacol. Exp. Ther 2001; 299(1): 187-197.

50. Coll R.C., Robertson A.A., Chae J.J., Higgins S.C., Muñoz-Planillo R., Inserra M.C., Vetter I., Dungan L.S., Monks B.G., Stutz A., Croker D.E., Butler M.S., Haneklaus M., Sutton C.E., Núñez G., Latz E., Kastner D.L., Mills K.H., Masters S.L., Schroder K., Cooper M.A., O'Neill L.A. A small-molecule inhibitor of the NLRP3 inflammasome for the treatment of inflammatory diseases. Nat. Med. 2015; 21(3): 248-255. DOI: $10.1038 / \mathrm{nm} .3806$

51. Youm Y.H., Nguyen K.Y., Grant R.W., Goldberg E.L., Bodogai M., Kim D., D’Agostino D., Planavsky N., Lupfer C., Kanneganti T.D., Kang S., Horvath T.L., Fahmy T.M., Crawford P.A., Biragyn A., Alnemri E., Dixit V.D. The ketone metabolite $\beta$-hydroxybutyrate blocks NLRP3 inflammasomemediated inflammatory disease. Nat. Med. 2015; 21(3): 263-269. DOI: 10.1038/nm.3804

52. Wannamaker W., Davies R., Namchuk M., Pollard J., Ford P., Ku G., Decker C., Charifson P., Weber P., Germann U.A., Kuida K., Randle J.C. (S)-1-((S)-2-\{[1-(4-amino-3-chloro-phenyl)-methanoyl]-amino\}-3,3-dimethyl-butanoyl)-pyrrolidine-2-carboxylic acid ((2R,3S)-2-ethoxy-5-oxo-tetrahydro-furan-3-yl)-amide (VX-765), an orally available selective interleukin converting enzyme/caspase-1 inhibitor, exhibits potent anti-inflammatory activities by inhibiting the release of IL-1 $\beta$ and IL-18. J. Pharmacol. Exp. Ther. 2007; 321(2): 509-516. DOI: 10.1124/jpet.106.111344

53. Zhang Y., Zheng Y. Effects and mechanisms of potent caspase-1 inhibitor VX765 treatment on collagen-induced arthritis in mice. Clin. Exp. Rheumatol. 2016; 34(1): 111-118.

54. Joosten L.A., Netea M.G., Fantuzzi G., Koenders M.I., Helsen M.M., Sparrer H., Pham C.T., van der Meer J.W., Dinarello C.A., van den Berg W.B. Inflammatory arthritis in caspase 1 gene-deficient mice: contribution of proteinase 3 to caspase 1-independent production of bioactive interleukin-1ß. Arthritis Rheum. 2009; 60(12): 36513662. DOI: 10.1002/art.25006

55. Монастырская Е., Лямина О., Малышев И.Ю. М1 и М2 фенотипы активированных макрофагов и их роль в иммунном ответе и патологии. Патогенез. 2008; 6(4): 31-39.

\section{References}

1. Kuo C.F., Grainge M.J., Zhang W., Doherty M. Global epidemiology of gout: prevalence, incidence and risk factors. Nat. Rev. Rheumatol. 2015; 11(11): 649-662. DOI:10.1038/nrrheum.2015.91

2. Nasonov S.L. [Rheumatology: Cynical Recommendations]. Moscow: GEOTAR-Media, 2008: 112-119. (in Russian)

3. Dalbeth N., Merriman T.R., Stamp L.K. Gout. Lancet. 2016; 388(10055): 2039-2052. DOI: 10.1016/S0140-6736(16)00346-9

4. Martinon F., Petrilli V., Mayor A., Tardivel A., Tschopp J. Gout-associated uric acid crystals activate the NLRP3 inflammasome. $\mathrm{Na}$ - ture. 2006; 440(7081): 237-224. DOI: 10.1038/nature04516

5. So A.K., Martinon F. Inflammation in gout: mechanisms and therapeutic targets. Nat. Rev. Rheumatol. 2017; 13(11): 639-647. DOI:10.1038/nrrheum.2017.155

6. Broz P., Dixit V.M. Inflammasomes: mechanism of assembly, regulation and signalling. Nat. Rev. Immunol. 2016; 16(7): 407-420. DOI: 10.1038/nri.2016.58

7. Liu-Bryan R., Scott P., Sydlaske A., Rose D.M., Terkeltaub R. Innate immunity conferred by Toll-like receptors 2 and 4 and myeloid differentiation factor 88 expression is pivotal to monosodium urate monohydrate crystal-induced inflammation. Arthritis Rheum. 2005; 52(9), 2936-2946. DOI: 10.1002/art.21238

8. Burns K., Martinon F., Tschopp J. New insights into the mechanism of IL-1 $\beta$ maturation. Curr. Opin. Immunol. 2003; 15(1): 26-30. DOI: 10.1016/s0952-7915(02)00017-1

9. Holzinger D., Nippe N., Vogl T., Marketon K., Mysore V., Weinhage T., Dalbeth N., Pool B., Merriman T., Baeten D., Ives A., Busso N., Foell D., Bas S., Gabay C., Roth J. Myeloid-related proteins 8 and 14 contribute to monosodium urate monohydrate crystal-induced inflammation in gout. Arthritis Rheum. 2014; 66(5): 1327-1339. DOI: 10.1002/ art.38369

10. Joosten L.A., Netea M.G., Mylona E., Koenders M.I., Malireddi R.K., Oosting M., Stienstra R., van de Veerdonk F.L., Stalenhoef A.F., Giamarellos-Bourboulis E.J., Kanneganti T.D., van der Meer J.W. Engagement of fatty acids with Toll-like receptor 2 drives interleukinlbeta production via the ASC/caspase 1 pathway in monosodium urate monohydrate crystal-induced gouty arthritis. Arthritis Rheum. 2010; 62(11): 3237-3248. DOI: 10.1002/art.27667

11. Schumacher H.R., Phelps P. Sequential changes in human polymorphonuclear leukocytes after urate crystal phagocytosis. An electron microscopic study. Arthritis Rheum. 1971; 14(4): 513-526. DOI: 10.1002/art.1780140411

12. PrabhuDas M.R., Baldwin C.L., Bollyky P.L., Bowdish D.M.E., Drickamer K., Febbraio M., Herz J., Kobzik L., Krieger M., Loike J., McVicker B., Means T.K., Moestrup S.K., Post S.R., Sawamura T., Silverstein S., Speth R.C., Telfer J.C., Thiele G.M., Wang X.Y., Wright S.D., El Khoury J. A consensus definitive classification of scavenger receptors and their roles in health and disease. J. Immunol. 2017; 198(10): 3775-3789. DOI: 10.4049/jimmunol.1700373

13. Shi Y., Mucsi A.D., Ng G. Monosodium urate crystals in inflammation and immunity. Immunol Rev. 2010; 233(1): 203-217. DOI: $10.1111 / \mathrm{j} .0105-2896.2009 .00851 . \mathrm{x}$

14. Tsugita M., Morimoto N., Tashiro M., Kinoshita K., Nakayama M. SR-B1 is asilica receptor that mediates canonical inflammasome activation. Cell Rep. 2017; 18(5): 1298-1311. DOI: 10.1016/j.celrep.2017.01.004

15. Ng G., Sharma K., Ward S.M., Desrosiers M.D., Stephens L.A., Schoel W.M., Li T., Lowell C.A., Ling C.C., Amrein M.W., Shi Y. Receptor-independent, direct membrane binding leads to cell-surfacelipid sorting and Syk kinase activation in dendritic cells. Immunity. 2008; 29(5): 807-818. DOI: 10.1016/j.immuni.2008.09.01

16. Nakayama M. Macrophage Recognition of Crystals and Nanoparticles. Front. Immunol. 2018; 9: 103. DOI: 10.3389/fimmu.2018.00103

17. Yaron J.R., Gangaraju S., Rao M.Y., Kong X., Zhang L., Su F., Tian Y., Glenn H.L., Meldrum D.R. $\mathrm{K}(+)$ regulates $\mathrm{Ca}(2+)$ to drive inflammasome signaling: dynamic visualization of ion flux in live cells. Cell Death Dis. 2015; 6, e1954. DOI: 10.1038/cddis.2015.277

18. Amaral F.A., Costa V.V., Tavares L.D., Sachs D., Coelho F.M., Fagundes C.T., Soriani F.M., Silveira T.N., Cunha L.D., Zamboni D.S., Quesniaux V., Peres R.S., Cunha T.M., Cunha F.Q., Ryffel B., Souza D.G., Teixeira M.M. NLRP3 inflammasome-mediated neutrophil recruitment and hypernociception depend on leukotriene B4 in a murine model of gout. Arthritis Rheum. 2012; 64(2): 474-484. DOI: $10.1002 /$ art. 33355

19. Shi H., Wang Y., Li X., Zhan X., Tang M., Fina M., Su L., Pratt D., Bu C.H., Hildebrand S., Lyon S., Scott L., Quan J., Sun Q., Russell J., Arnett S., Jurek P., Chen D., Kravchenko V.V., Mathison J.C., Moresco E.M., Monson N.L., Ulevitch R.J., Beutler B. NLRP3 activation and mitosis are mutually exclusive events coordinated by NEK7, a new inflammasome component. Nat. Immunol. 2016; 17(3), 250-258. DOI: $10.1038 /$ ni. 3333

20. Cai X., Chen J., Xu H., Liu S., Jiang Q.X., Halfmann R., Chen Z.J. Prion-like polymerization underlies signal transduction in antiviral immune defense and inflammasome activation. Cell. 2014; 156(6): 1207-1222. DOI: 10.1016/j.cell.2014.01.063 
21. Aglietti R.A., Dueber E.C. Recent insights into the molecular mechanisms underlying pyroptosis and gasdermin family functions. Trends Immunol. 2017; 38(4): 261-271. DOI: 10.1016/j.it.2017.01.003

22. Kayagaki N., Stowe I.B., Lee B.L., O'Rourke K., Anderson K., Warming S., Cuellar T., Haley B., Roose-Girma M., Phung Q.T., Liu P.S., Lill J.R., Li H., Wu J., Kummerfeld S., Zhang J., Lee W.P., Snipas S.J., Salvesen G.S., Morris L.X., Fitzgerald L., Zhang Y., Bertram E.M., Goodnow C.C., Dixit V.M. Caspase-11 cleaves gasdermin D for non-canonical inflammasome signalling. Nature.2015; 526(7575): 666-671. DOI: $10.1038 /$ nature 15541

23. Braga T.T., Forni M.F., Correa-Costa M., Ramos R.N., Barbuto J.A., Branco P., Castoldi A., Hiyane M.I., Davanso M.R., Latz E., Franklin B.S., Kowaltowski A.J., Camara N.O. Soluble uric acid activates the NLRP3 inflammasome. Sci. Rep. 2017; 7: 39884. DOI: $10.1038 /$ srep39884

24. Crisan T.O., Cleophas M.C., Oosting M., Lemmers H., Toenhake-Dijkstra H., Netea M.G., Jansen T.L., Joosten L.A. Soluble uric acid primes TLR-induced proinflammatory cytokine production by human primary cells via inhibition of IL-1Ra. Ann. Rheum. Dis. 2016; 75(4): 755-762. DOI: 10.1136/annrheumdis-2014-206564

25. Netea M.G., van de Veerdonk F.L., van der Meer J.W., Dinarello C.A., Joosten L.A. Inflammasome-independent regulation of IL-1-family cytokines. Annu. Rev. Immunol. 2015; 33: 49-77. DOI: 10.1146/annurev-immunol-032414-112306

26. Echtermeyer F., Bertrand J., Dreier R., Meinecke I., Neugebauer K., Fuerst M., Lee Y.J., Song Y.W., Herzog C., Theilmeier G., Pap T. Syndecan-4 regulates ADAMTS-5 activation and cartilage breakdown in osteoarthritis. Nat. Med. 2009; 15(9): 1072-1076. DOI: 10.1038/nm.1998

27. Irmler M., Hertig S., MacDonald H.R., Sadoul R., Becherer J.D., Proudfoot A., Solari R., Tschopp J. Granzyme A is an interleukin 1ß-converting enzyme. J. Exp. Med. 1995; 181(5): 1917-1922. DOI: 10.1084/jem.181.5.1917

28. So A., Dumusc A., Nasi S. The role of IL-1 in gout: from bench to bedside. Rheumatology (Oxford). 2018; 57(Suppl_1): i12-i19. DOI: 10.1093/rheumatology/kex449

29. Schlesinger N., Thiele R.G. The pathogenesis of bone erosions in gouty arthritis. Ann. Rheum. Dis. 2010; 69(11): 1907-1912. DOI: 10.1136/ard.2010.128454

30. Dinarello C.A. Infection, fever, and exogenous and endogenous pyrogens: some concepts have changed. J. Endotoxin Res. 2004; 10(4): 201-222. DOI: $10.1177 / 09680519040100040301$

31. Dinarello C.A. Immunological and inflammatory functions of the interleukin-1 family. Аnnu. Rev. Immunol. 2009; 27: 519-550. DOI: 10.1146/annurev.immunol.021908.132612

32. Dumusc A., So A. Interleukin-1 as a therapeutic target in gout Curr. Opin. Rheumatol. 2015; 27(2): 156-163. DOI: 10.1097 BOR.0000000000000143

33. Kienhorst L.B., van Lochem E., Kievit W., Dalbeth N., Merriman M.E., Phipps-Green A., Loof A., van Heerde W., Vermeulen S., Stamp L.K., van Koolwijk E., de Graaf J., Holzinger D., Roth J., Janssens H.J., Merriman T.R., Broen J.C., Janssen M., Radstake T.R. Gout is a chronic inflammatory disease in which high levels of interleukin-8 (CXCL8), myeloid-related protein 8/myeloid-related protein 14 complex, and an altered proteome are associated with diabetes mellitus and cardiovascular disease. Arthritis Rheumatol. 2015; 67(12): 3303-3313. DOI: 10.1002/art.39318

34. Popa-Nita O., Naccache P.H. Crystal-induced neutrophil activation. Immunol. Cell Biol. 2010; 88(1): 32-40. DOI: 10.1038/icb.2009.98

35. Carling D. AMPK signalling in health and disease. Curr. Opin. Cell Biol. 2017; 45: 31-37. DOI: 10.1016 / j.ceb.2017.01.005

36. Wang Y., Viollet B., Terkeltaub R., Liu-Bryan R. AMP-activated protein kinase suppresses urate crystal-induced inflammation and transduces colchicine effects in macrophages. Ann. Rheum. Dis. 2016; 75(1): 286-294. DOI: 10.1136/annrheumdis-2014-206074

37. Chen Y.H., Hsieh S.C., Chen W.Y., Li K.J., Wu C.H., Wu P.C., Tsai C.Y., Yu C.L. Spontaneous resolution of acute gouty arthritis is associated with rapid induction of the anti-inflammatory factors TGFB1, IL-10 and soluble TNF receptors and the intracellular cytokine negative regulators CIS and SOCS3. Ann. Rheum. Dis. 2011; 70(9): 1655-1663. DOI: 10.1136/ard.2010.145821

38. Lioté F., Prudhommeaux F., Schiltz C., Champy R., Herbelin A., Ortiz-Bravo E., Bardin T. Inhibition and prevention of monosodium urate monohydrate crystal-induced acute inflammation in vivo by transforming growth factor $\beta 1$. Arthritis Rheum. 1996; 39(7): 11921198. DOI: $10.1002 /$ art. 1780390718
39. Galvão I, Vago J.P., Barroso L.C., Tavares L.P., Queiroz-Junior C.M., Costa V.V., Carneiro F.S., Ferreira T.P., Silva P.M., Amaral F.A., Sousa L.P., Teixeira M.M. Annexin A1 promotes timely resolution of inflammation in murine gout. Eur. J. Immunol. 2017; 47(3): 585-596. DOI: 10.1002/eji.201646551

40. Ter Horst R., Jaeger M., Smeekens S.P., Oosting M., Swertz M.A., Li Y., Kumar V., Diavatopoulos D.A., Jansen A.F.M., Lemmers H., Toenhake-Dijkstra H., van Herwaarden A.E., Janssen M., van der Molen R.G., Joosten I., Sweep F.C.G.J., Smit J.W., NeteaMaier R.T., Koenders M.M.J.F., Xavier R.J., van der Meer J.W.M., Dinarello C.A., Pavelka N., Wijmenga C., Notebaart R.A., Joosten L.A.B., Netea M.G.. Host and environmental factors influencing individual human cytokine responses. Cell. 2016; 167(4): 1111-1124. e13. DOI: $10.1016 /$ j.cell.2016.10.018

41. Elliot A.J., Cross K.W., Fleming D.M. Seasonality and trends in the incidence and prevalence of gout in England and Wales 19942007. Ann. Rheum. Dis. 2009; 68(11): 1728-1733. DOI: 10.1136/ ard.2008.096693

42. Joosten L.A., Crișan T.O., Azam T., Cleophas M.C., Koenders M.I., van de Veerdonk F.L., Netea M.G., Kim S., Dinarello C.A. Alpha-1-anti-trypsin-Fc fusion protein ameliorates gouty arthritis by reducing release and extracellular processing of IL-1 $\beta$ and by the induction of endogenous IL-1Ra. Ann. Rheum. Dis. 2016; 75(6): 1219-1227. DOI: 10.1136/annrheumdis-2014-206966

43. Schauer C., Janko C., Munoz L.E., Zhao Y., Kienhöfer D., Frey B., Lell M., Manger B., Rech J., Naschberger E., Holmdahl R., Krenn V., Harrer T., Jeremic I., Bilyy R., Schett G., Hoffmann M., Herrmann M. Aggregated neutrophil extracellular traps limit inflammation by degrading cytokines and chemokines. Nat. Med. 2014; 20(5): 511-517. DOI: $10.1038 / \mathrm{nm} .3547$

44. Desai J., Kumar S.V., Mulay S.R., Konrad L., Romoli S., Schauer C., Herrmann M., Bilyy R., Müller S., Popper B., Nakazawa D., Weidenbusch M., Thomasova D., Krautwald S., Linkermann A., Anders H.J. PMA and crystal-induced neutrophil extracellular trap formation involves RIPK1-RIPK3-MLKL signaling. Eur. J. Immunol. 2016; 46(1): 223-229. DOI: 10.1002/eji.201545605

45. Jhang J.J., Lu C.C., Yen G.C. Epigallocatechin gallate inhibits urate crystals-induced peritoneal inflammation in C57BL/6 mice. Mol. Nutr. Food Res. 2016; 60(10): 2297-2303. DOI: 10.1002/mnfr.201600106

46. Dhanasekar C., Kalaiselvan S., Rasool M. Morin, a bioflavonoid suppresses monosodium urate crystalinduced inflammatory immune response in RAW 264.7 macrophages through the inhibition of inflammatory mediators, intracellular ROS levels and NF- $x \mathrm{~B}$ activation. PLoS ONE. 2015; 10(12): e0145093. DOI: 10.1371/journal.pone.0145093

47. Kim S.K., Choe J.Y., Park K.Y. Rebamipide suppresses monosodium urate crystal-induced interleukin-1 $\beta$ production through regulation of oxidative stress and caspase-1 in THP-1 cells. In flammation. 2016; 39(1): 473-482. DOI: 10.1007/s10753-015-0271-5

48. Ives A., Nomura J., Martinon F., Roger T., LeRoy D., Miner J.N., Simon G., Busso N., So A. Xanthine oxidoreductase regulates macrophage IL-1 $\beta$ secretion upon NLRP3 inflammasome activation. Nat. Commun. 2015; 6: 6555. DOI: 10.1038 / ncomms7555

49. Perregaux D.G., McNiff P., Laliberte R., Hawryluk N., Peurano H., Stam E., Eggler J., Griffiths R., Dombroski M.A., Gabel C.A. Identification and characterization of a novel class of interleukin-1 post-translational processing inhibitors. J. Pharmacol. Exp. Ther. 2001; 299(1): 187-197.

50. Coll R.C., Robertson A.A., Chae J.J., Higgins S.C., Muñoz-Planillo R., Inserra M.C., Vetter I., Dungan L.S., Monks B.G., Stutz A., Croker D.E., Butler M.S., Haneklaus M., Sutton C.E., Núñez G., Latz E., Kastner D.L., Mills K.H., Masters S.L., Schroder K., Cooper M.A., O'Neill L.A. A small-molecule inhibitor of the NLRP3 inflammasome for the treatment of inflammatory diseases. Nat. Med. 2015; 21(3): 248-255. DOI: $10.1038 / \mathrm{nm} .3806$

51. Youm Y.H., Nguyen K.Y., Grant R.W., Goldberg E.L., Bodogai M., Kim D., D’Agostino D., Planavsky N., Lupfer C., Kanneganti T.D., Kang S., Horvath T.L., Fahmy T.M., Crawford P.A., Biragyn A., Alnemri E., Dixit V.D. The ketone metabolite $\beta$-hydroxybutyrate blocks NLRP3 inflammasomemediated inflammatory disease. Nat. Med. 2015; 21(3): 263-269. DOI: 10.1038/nm.3804

52. Wannamaker W., Davies R., Namchuk M., Pollard J., Ford P., Ku G., Decker C., Charifson P., Weber P., Germann U.A., Kuida K., Randle J.C. (S)-1-((S)-2-\{[1-(4-amino-3-chloro-phenyl)-methanoyl]-amino\}-3,3-dimethyl-butanoyl)-pyrrolidine-2-carboxylic acid 
((2R,3S)-2-ethoxy-5-oxo-tetrahydro-furan-3-yl)-amide (VX-765), an orally available selective interleukin converting enzyme/caspase-1 inhibitor, exhibits potent anti-inflammatory activities by inhibiting the release of IL-1 $\beta$ and IL-18. J. Pharmacol. Exp. Ther. 2007; 321(2): 509-516. DOI: 10.1124/jpet.106.111344

53. Zhang Y., Zheng Y. Effects and mechanisms of potent caspase- 1 inhibitor VX765 treatment on collagen-induced arthritis in mice. Clin. Exp. Rheumatol. 2016; 34(1): 111-118.
54. Joosten L.A., Netea M.G., Fantuzzi G., Koenders M.I., Helsen M.M., Sparrer H., Pham C.T., van der Meer J.W., Dinarello C.A., van den Berg W.B. Inflammatory arthritis in caspase 1 gene-deficient mice: contribution of proteinase 3 to caspase 1-independent production of bioactive interleukin-1ß. Arthritis Rheum. 2009; 60(12): 3651-3662. DOI: 10.1002/art.25006

55. Monastyrskaya E., Lyamina O., Malyshev I.Yu. [M1 and M2 phenotypes of activated macrophages and their role in immune response and pathology]. Patogenez. [Pathogenesis]. 2008; 6(4): 31-39. (in Russian)

\section{Сведения об авторах:}

Малышев Игорь Юрьевич - доктор медицинских наук, заведующий кафедрой патологической физиологии Федерального государственного бюджетного образовательного учреждения высшего образования «Московский государственный медико-стоматологический университет имени А.И. Евдокимова» Министерства здравоохранения Российской Федерации; заведующий лабораторией регуляторных механизмов стресса и адаптации Федерального государственного бюджетного научного учреждения «Научно-исследовательский институт общей патологии и патофизиологии»; http://orcid.org/0000-0002-2381-9612

Пихлак Андрей Эдуардович - доктор медицинских наук, профессор, заведующий кафедрой ревматологии и медико-социальной реабилитации Федерального государственного бюджетного образовательного учреждения высшего образования «Московский государственный медико-стоматологический университет имени А.И. Евдокимова» Министерства здравоохранения Российской Федерации

Буданова Ольга Петровна - старший научный сотрудник лаборатории регуляторных механизмов стресса и адаптации Федерального государственного бюджетного научного учреждения «Научно-исследовательский институт общей патологии и патофизиологии»; https://orcid.org/0000-0002-6650-5082 